\title{
Unconventional accelerated thermal ageing test for traction electric motors in vehicles
}

\author{
Luca Lusuardi and Andrea Cavallini \\ DEI, University of Bologna \\ Bologna, Italy \\ E-mail: luca.lusuardi4@unibo.it
}

\author{
Vincenzo Madonna, Paolo Giangrande and Michael Galea \\ PEMC Group, University of Nottingham \\ Nottingham, United Kingdom \\ E-mail: Vincenzo.madonna1@nottingham.ac.uk
}

\begin{abstract}
Car manufacturers are increasingly working to make the all-electric car a reliable and affordable mobility option for a larger section of the population. However, several issues need to be addressed before achieving this goal. One of the problems is represented by the qualification of the insulation systems employed in electric motors. Unfortunately, the tests to be performed are time consuming and the design of such measurements very often is done by trial and error, further lengthening the validation phase. In addition, since cars are exposed to variable torque and speed operations (especially when driven in city traffic), the stator winding temperature is expected to vary in a wide range. Nevertheless, indications regarding the impact that highly variable temperature conditions play on the insulation reliability are not available, at the moment. In this work, the results of accelerated thermal aging tests using temperature profiles (i.e. variable temperature ageing) are presented and discussed. The experiments are accomplished on simplified insulation systems for electric motor (i.e. specimens) and cycling temperature profiles, ranging between $200^{\circ} \mathrm{C}-260^{\circ} \mathrm{C}$ and featuring different thermal gradients, are applied as ageing stress. Finally, the possibility of relying on statistical techniques for improving the quality of prediction, while shortening the testing time, is explored.
\end{abstract}

Keywords-Partial Discharges, Low-voltage motors, Accelerated thermal test, Insulation ageing, Thermal transient, Temperature Index, More Electric Aircraft, More Electric Vehicle

\section{INTRODUCTION}

In recent years, there has been an increasing push towards the adoption of hybrid vehicles, if not fully electric. This is leading to a drastic enhance in research on the development of technologies that would increase the performance and the power density of low-voltage electric motors [1].

In this regard, the electrical insulation of stator (and possibly rotor) plays an important role and today a field of research is focusing on how to avoid its over-engineering for all kinds of vehicles (i.e. cars, ships and aircraft). In particular, a greater quantity of insulation inside the stator slots, with the same wire diameter, means a lower fill-factor [2] and a worse heat dissipation inside the motor (which may force the adoption of dedicated hydraulic circuits) $[3,4]$.

This work has received funding from the Clean Sky 2 Joint Undertaking under the European Union's Horizon 2020 research and innovation programme under grant agreement no. 807081.

This work was also funded by the University of Nottingham's Propulsion Futures Beacon.
At the same time, always to ensure the highest possible performance, the supply voltages and frequencies have also risen, allowing a compact motor design [5]. However, greater voltage levels and switching frequencies introduce new challenges in the field of low-voltage insulation. For instance, the use of innovative silicon carbide mosfet (SiC-MOSFET) causes higher inverter slew rates compared to conventional silicon insulated gate bipolar transistor (Si-IGBT). The resulting overvoltages at the machine terminals place significant strain on the insulation and can unintentionally trigger partial discharge (PD) activity, which quickly leads to catastrophic failure of the entire system [6].

It is known from the literature that if there are electric failures within the machine, these are generally attributable to the winding $[7,8]$, which is the most critical subsystem. Hence, electric motors designers and manufacturers are currently lacking of an updated procedure for properly sizing and then qualifying the winding insulation system, that includes the frequent thermal transients faced by machines employed in the context of transportation electrification.

In fact, the standards [9-11] indicate that qualification tests and accelerated ageing of insulating systems should always be carried out using a constant temperature. However, most of the electric motors and actuators that will be installed in cars, aircraft or ships will operate intermittently (i.e. the steady-state temperature is not expected to be reached), and therefore it is necessary to investigate in advance whether such operating condition will have an impact on their useful life.

In this work several accelerated thermal ageing tests have been carried out, where the specimens are exposed to thermal cycles featuring temperature profiles ranging from $200^{\circ} \mathrm{C}$ to $260^{\circ} \mathrm{C}$ with different time periods. The aim of this unconventional campaign test consists in investigating and evaluating the effect of thermal cycling on enamelled wire insulation. Further, the collected data have been post-processed and the obtained outcomes have been employed for verifying the effectiveness of the implemented unconventional test procedure, in the evaluation of the insulation thermal performance. For the insulation system under examination, the findings ensuing from the unconventional tests have been referred to the guidelines suggested by the current technical standards. The final objective of such comparative analysis consists in formalizing a new type of experiment, similar to the one defined by IEC 60172, which accounts for the frequent temperature variations and allows a rapid thermal qualification. 


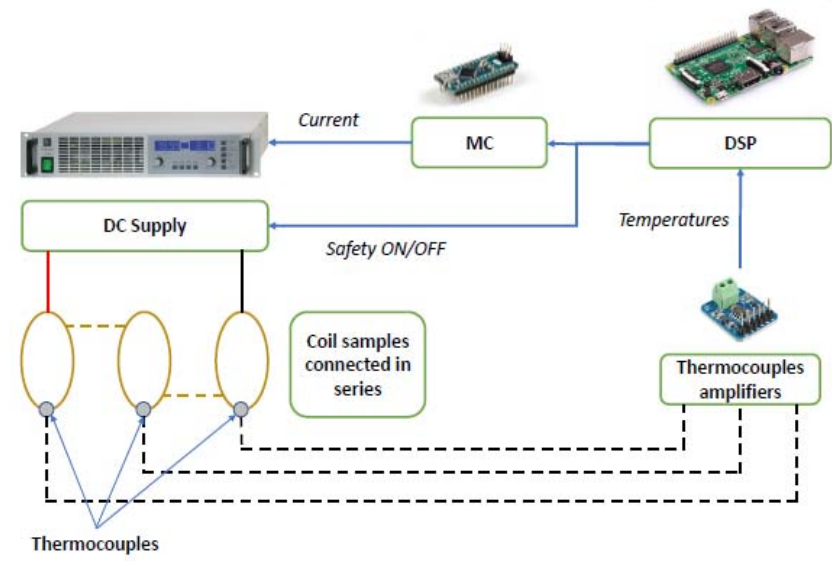

Fig. 1. Diagram of the accelerated cycling thermal ageing test bench.

TABLE I. WIRE CHARACTERISTICS

\begin{tabular}{cc}
\hline Parameter & Value \\
\hline Copper core diameter & $0.4 \mathrm{~mm}$ \\
Insulation grade & 2 \\
Minimum insulation thickness & $20 \mu \mathrm{m}$ \\
Insulation basecoat & Polyesterimide \\
Insulation overcoat & Polyamide-imide \\
\hline
\end{tabular}

\section{EXPERIMENTAL SETUP}

The simplified scheme of the ageing test bench is depicted in Fig. 1. To heat the samples so as to ensure that they follow the desired temperature profile, the Joule effect resulting from the current flowing within the wire and imposed by a programmable DC power supply is exploited.

Through four K-type thermocouples in intimate contact with the wires of four different specimens, the temperature trend is monitored. The acquired temperatures are elaborated by a digital signal processor (DSP). At the same time, the current is effectively modulated by a microcontroller (MC) connected to the DSP in order to keep the thermal slew rate $(d \theta / d t)$ constant throughout the test campaign.

\section{A. Test Specimens}

Based on the same premises as in work [12], specimens consisting of random wound coils were tested. Table I summarises the properties of the wire used, while Table II shows the samples' main characteristics. The coils were hung on a PTFE rod and inserted into a fume hood with variable air flow rate. The two strands were joined together with Kapton ${ }^{\circledR}$ adhesive tape (thermal class 220) to ensure their contact during voltage testing.

\section{B. Temperature exposure}

Since the effect of the thermal slew rate (i.e. thermal gradient) is meant to be investigated, it was decided to carry out three tests in which the applied temperature profile ranged from $200^{\circ} \mathrm{C}$ to $260^{\circ} \mathrm{C}$ at three different thermal gradients: $0.5^{\circ} \mathrm{C} / \mathrm{s}$, $2.5^{\circ} \mathrm{C} / \mathrm{s}$ and $4^{\circ} \mathrm{C} / \mathrm{s}$. Fig. 2 gives the actual temperature trend for each of the cases examined.

The temperature limit of $260^{\circ} \mathrm{C}$ has been chosen on the basis of the IEC 60034-18-21 indications.
TABLE II. COIL SPECIMEN FEATURES

\begin{tabular}{cc}
\hline Parameter & Value \\
\hline Thermal class & $200{ }^{\circ} \mathrm{C}$ \\
Number of turns & 20 \\
Strand in parallel & 2 \\
Average turn length & $250 \mathrm{~mm}$ \\
\hline
\end{tabular}
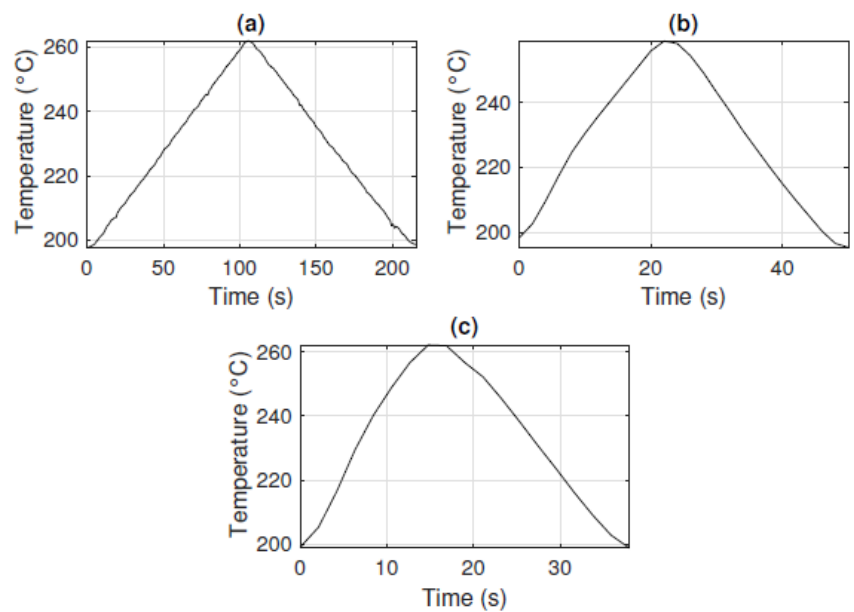

Fig. 2. Temperature profiles for (a) $0.5^{\circ} \mathrm{C} / \mathrm{s}$, (b) $2.5^{\circ} \mathrm{C} / \mathrm{s}$ and (c) $4^{\circ} \mathrm{C} / \mathrm{s}$.

\section{Test voltage and its application}

The insulation of the specimens has been assessed by monitoring the degradation rate of an electrical property via a non-destructive test, in accordance with IEC 60216-1.

Therefore, every 20 hours, the samples were disconnected from the DC power supply, restored to room temperature by means of uncontrolled air cooling and the partial discharge inception voltage $(P D I V)$ test was performed on each of them. Completed the PDIV measurement, the samples are then reconnected to the ageing test bench and a new thermal cycle is run.

The $P D I V$ was considered the most appropriate property to monitor, given the application for which the electrical machines are designed (i.e. inverter-fed electric motor). In fact, in lowvoltage motors, which are equipped with organic insulation (socalled type-I), partial discharge activity is not allowed for their entire service life [13].

\section{End-of-life criterion}

As mentioned above, low-voltage motors are not permitted to incept PDs at any time during their service life, since they are equipped with type-I insulation. Therefore, the end-of-life criterion was considered to be the moment when a tested specimen is characterized by a $P D I V$ below a certain threshold.

TABLE III. INSULATION SYSTEM WORKING CONDITIONS

\begin{tabular}{cc}
\hline Parameter & Data \\
\hline Max DC link voltage & $540 \mathrm{~V}$ \\
Insulation Thermal Class & $200^{\circ} \mathrm{C}$ \\
Overvoltage Stress category & $\mathrm{C}$ \\
Average rise time & $200 \mathrm{~ns}$ \\
\hline
\end{tabular}




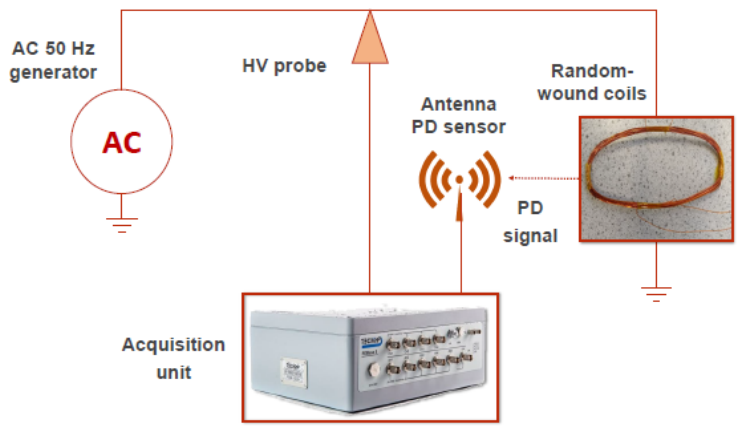

Fig. 3. Diagram of PDIV test.

To determine the latter value, some assumptions were made about the possible characteristics of the electric drive components (i.e. electric motor, power converter, connecting cables, etc..). They are summarized in Table III.

Referring once again to IEC 60034-18-41, the limit voltage (i.e. $P D I V_{\min }$ ) was determined according to (1)

$$
P D I V_{\text {min }}=W F \times O F \times E F \times V_{D C}=436 V_{r m s}
$$

where $W F$ is the winding factor (equal to 0.7 for the turn-to-turn insulation), $O F$ is the overshooting factor (corresponding to 2 for stress category $\mathrm{C}$ ), $E F$ is the enhancement factor depending on thermal class and grounding (equal to 1.63 following the data listed in Table III) and $V_{D C}$ the DC-bus voltage.

\section{CAlculations AND Results}

For each test cycle, as indicated by IEC 60216-1, the mean value of the $P D I V$ has been calculated. On the other hand, since in the automotive sector, and even more so in the aerospace one, the risk of failure is expected to be very low (i.e. safety-critical applications requires modest probability of failure), it was also considered appropriate to bring all the test sets back into a Weibull distribution and extract the so-called $B-10$ life [14], i.e. the time to wait because statistically $10 \%$ of the test specimens compared to the initial population fails.

Figs. 4, 5 and 6 show the development of the PDIV over time for the three different thermal slew rates. Table IV lists the Time-To-Failure (deductible from the graphs) considering, in one case, the average value of the PDIV (i.e. $T T F_{I E C}$ ) and, in the other, the value of B10-life (i.e. $T T F_{B 10}$ ).

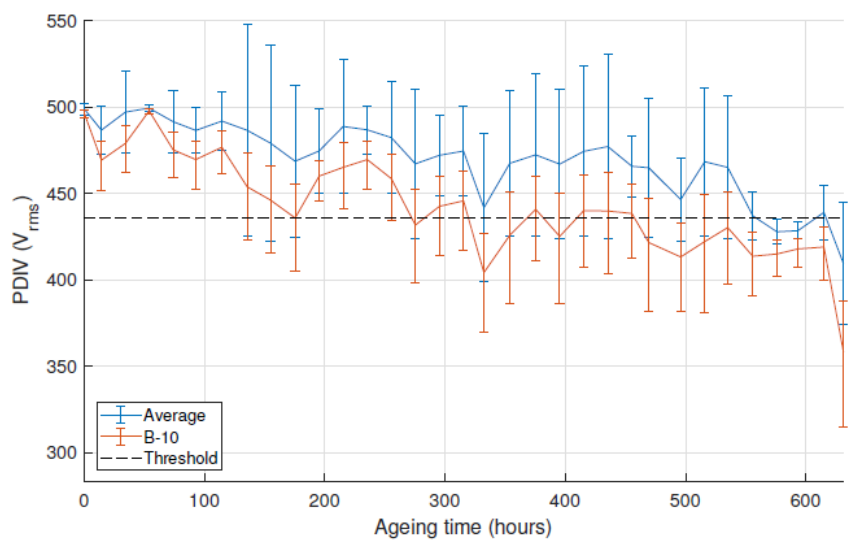

Fig. 4. PDIV monitoring during the accelerated thermal ageing at $0.5^{\circ} \mathrm{C} / \mathrm{s}$.

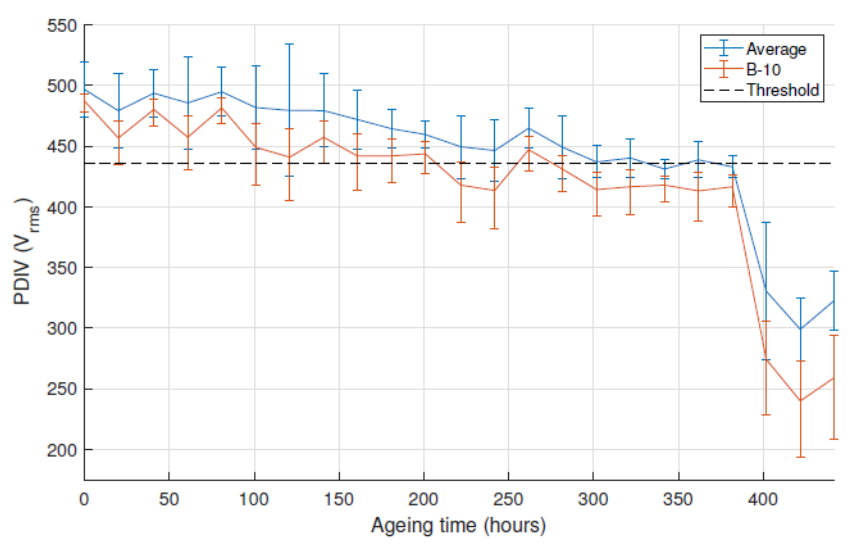

Fig. 5. PDIV monitoring during the accelerated thermal ageing at $2.5^{\circ} \mathrm{C} / \mathrm{s}$.

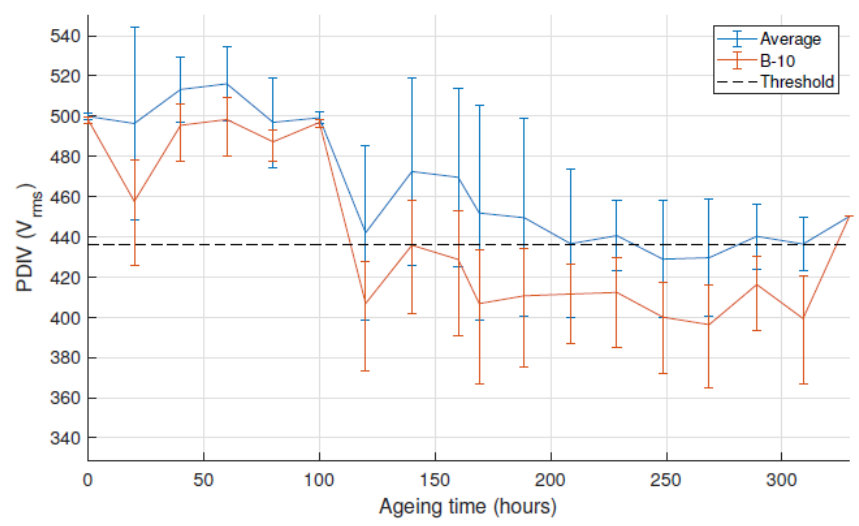

Fig. 6. PDIV monitoring during the accelerated thermal ageing at $4{ }^{\circ} \mathrm{C} / \mathrm{s}$.

TABLE IV. SUMMARY OF THE TIME-TO-FAILURE FOR THE THREE DIFFERENT ACCELERATED THERMAL AGING TESTS

\begin{tabular}{ccc}
\hline $\begin{array}{c}\mathbf{d} \mathbf{\theta} / \mathbf{d t} \\
{ }^{\circ} \mathrm{C} / \mathrm{s}\end{array}$ & $\begin{array}{c}\mathbf{T T F}_{\text {IEC }} \\
\mathrm{h}\end{array}$ & $\begin{array}{c}\mathbf{T T F}_{\text {B10 }} \\
\mathrm{h}\end{array}$ \\
\hline 0.5 & 555.9 & 275.0 \\
2.5 & 431.1 & 221.7 \\
4 & 248.5 & 120 \\
\hline
\end{tabular}

Looking at Figs. 4, 5 and 6, the trend of the two PDIV curves (i.e. average and B-10) is almost identical, as expected. However, it is more important to point out that the service life of the specimens is drastically shortened with the increase of the thermal slew rate. In particular, the service life is reduced by more than $50 \%$, when the results regarding the temperature profile featuring $4^{\circ} \mathrm{C} / \mathrm{s}$ are compared to those relatetive to $0.5^{\circ} \mathrm{C} / \mathrm{s}$. Despite what has been typically done so far, for relatively short cycle times the outcome of the unconventional tests proved that considering the only average value of the temperature profile is not sufficient. Indeed, it is also necessary to take into account the effect of thermal transients (i.e. temperature profile gradient).

\section{DISCUSSION}

Until now, standards and literature have always considered cases of insulating systems ageing with very slow thermal transients (e.g. high voltage cables for electrical distribution or 
large rotating machines) $[15,16]$. In these cases, when the thermal ageing is analysed, only the effect of the temperature is considered, since other effects (e.g. thermal slew rate) are overlaid by the one of the operating temperature at steady-state. Further, in some circumstances, even an average temperature calculated over the entire service life is directly used.

Due to the inherent nature of the transportation applications, the employed low-voltage motors will be exposed to frequent thermal transients [17], therefore, it is no longer sufficient to consider accelerated thermal ageing tests carried out at a constant temperature. In particular, in the previous section, it has been demonstrated the key role played by the speed of temperature variation (i.e. thermal gradient) on the service life of the motor insulation and how significant is its impact.

The drastic service life shortening might be explained by referring to the polyamide-imide (so-called PAI) fatigue and tensile curves as a function of the temperature, which are reported in Figs. 7 and 8 [18] for sake of completeness. The PAI is often utilized for overcoating enamelled wires that already feature a polyesterimide (PEI) basecoat. In fact, the PAI topcoat improves the magnet wire properties by ensuring a better abrasion resistance along with an enhanced temperature resistance [19].

The tensile curve determines how much a material can stretch, under a certain pressure, up to the so-called ultimate tensile strength. In the case of PAI, it can be seen that at room temperature the polymer shows an almost completely elastic behaviour, while at higher temperatures the curve shows a much more plastic trend. This means that at high temperatures (in particular above $200^{\circ} \mathrm{C}$ ) the short-time thermal cycles are likely to give rise to strong stresses due to effects of mechanical hysteresis. This hypothesis is consistent with the fatigue curves, which establish the number of cycles that the PAI can withstand when subjected to a certain periodic stress: as the temperature rises, the number of cycles at break decreases with the same intensity of stress.

Based on such evidence, when the insulation is subject to sudden changes in temperature (i.e. temperature profile with remarkable thermal slew rate), the enamel is not only stressed from a thermal point of view, but also on a mechanical one.

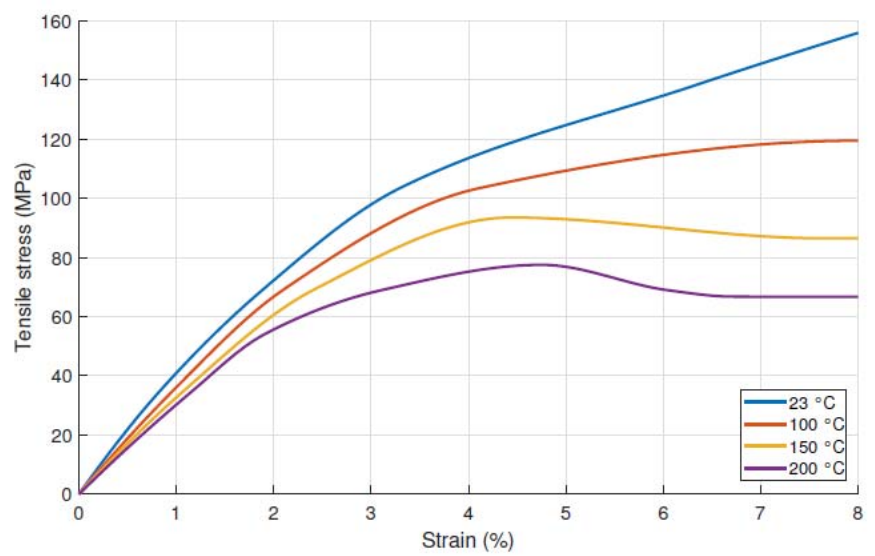

Fig. 7. Stress-strain in tension for Torlon $^{\circledR}$ PAI 4203LF over a broadtemperature range [18].

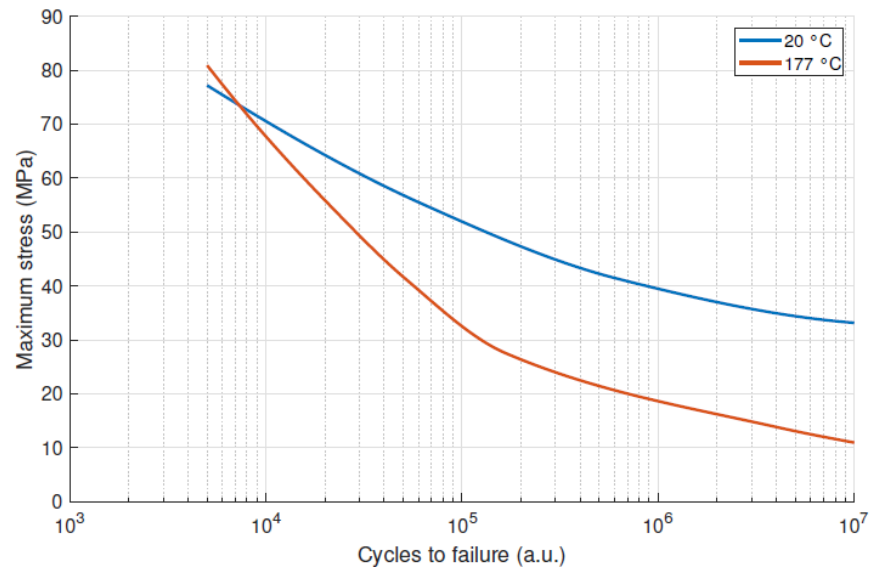

Fig. 8. Flexural fatigue strength of Torlon ${ }^{\circledR}$ PAI $4203 \mathrm{LF}$ resins at $30 \mathrm{~Hz}$ for two different temperature levels [18].

Therefore, in the future it is likely that in addition to the constant temperature ageing tests, further tests will have to be carried out in order to take into account the mechanical stresses due to the rapid expansion and thermal compression of the windings' insulating enamel. This could be done by providing temperature profiles characterized by thermal gradients similar to those expected in the specific application [20], or with mechanical fatigue tests at defined operating temperatures.

\section{CONCLUSIONS}

Accelerated thermal ageing tests were conducted through temperature profiles resembling the rapid load variations experienced by low-voltage motors installed in the more electric transportation framework. In particular, the chosen ageing stress (i.e. temperature profile) varies cyclically between $200^{\circ} \mathrm{C}$ and $260^{\circ} \mathrm{C}$ and features three different thermal slew rates (i.e. $0.5^{\circ} \mathrm{C} / \mathrm{s}, 2.5^{\circ} \mathrm{C} / \mathrm{s}$ and $4^{\circ} \mathrm{C} / \mathrm{s}$ ). The experimental findings shown the drastic impact of temperature profiles on the strand to strand insulation lifetime.

At the same time, it is believed that, for short-time duty applications, it is more effective to perform tests considering B10-lives, rather than arithmetic mean or logarithmic arithmetic mean, as suggested by IEC 60216-1. This choice has a twofold advantage: on the one hand it allows testing to be carried out more quickly, while on the other hand, it provides a degree of reliability closer to the needs of the transport manufacturing industries. Indeed, an even stricter constraint could be adopted, such as B1-life.

Given the mechanical properties of the polymeric materials used for winding enamels (typically polyamide-imide), the influence of high thermal slew rates is probably due to a phenomenon of low cycle fatigue. However, further mechanical and thermal investigations are necessary to support the latter deduction.

\section{REFERENCES}

[1] V. Madonna, P. Giangrande, W. Zhao, G. Buticchi, H. Zhang, C. Gerada, et al., "Reliability vs. Performances of Electrical Machines: Partial Discharges Issue," in 2019 IEEE Workshop on Electrical Machines Design, Control and Diagnosis (WEMDCD), Athens, Greece, 2019, pp. 77-82. 
[2] V. Madonna, P. Giangrande, W. Zhao, H. Zhang, C. Gerada and M. Galea, "On the Design of Partial Discharge-Free Low Voltage Electrical Machines," in 2019 IEEE International Electric Machines and Drives Conference (IEMDC), San Diego, CA, USA, 2019, pp. 1837-1842.

[3] J. Pyrhonen, T. Jokinen and V. Hrabovcova, "Design of rotating electrical machines," John Wiley \& Sons, 2013.

[4] V. Madonna, A. Walker, P. Giangrande, C. Gerada, G. Serra, and M. Galea, "Improved thermal management and analysis for stator end-windings of electrical machines," in IEEE Transactions on Industrial Electronics, vol. 66, no. 7, pp. 50575069, July 2019.

[5] V. Madonna, G. Migliazza, P. Giangrande, E. Lorenzani, G. Buticchi and M. Galea, "The Rebirth of the Current Source Inverter: Advantages for Aerospace Motor Design," IEEE Industrial Electronics Magazine, vol. 13, no. 4, pp. 65-76, Dec. 2019.

[6] L. Lusuardi, A. Cavallini, M. G. de la Calle, J. M. MartinezTarifa and G. Robles, "Insulation design of low voltage electrical motors fed by PWM inverters," in IEEE Electrical Insulation Magazine, vol. 35, no. 3, pp. 7-15, May-June 2019.

[7] M. Kaufhold, G. Borner, M. Eberhardt and J. Speck, "Failure mechanism of the interturn insulation of low voltage electric machines fed by pulse-controlled inverters," in IEEE Electrical Insulation Magazine, vol. 12, no. 5, pp. 9-16, Sept.-Oct. 1996.

[8] G. C. Stone, I. Culbert, E. A. Boulter, and H. Dhirani, "Electrical Insulation for Rotating Machines: Design, Evaluation, Aging, Testing, and Repair," Wiley, 2014.

[9] IEC 60172, "Test procedure for the determination of the temperature index of enamelled and tape wrapped winding wires," 2015.

[10] IEC 60216-1, "Electrical insulating materials - Thermal endurance properties - Part 1:Ageing procedures and evaluation of test results," 2013.

[11] IEC 60034-18-21, "Rotating electrical machines - Part 18-21: Functional evaluation of insulation systems - Test procedures for wire-wound windings - Thermal evaluation and classification, " 2013.

[12] V. Madonna, P. Giangrande, L. Lusuardi, A. Cavallini, C. Gerada and M. Galea, "Thermal overload and insulation aging of short duty cycle, aerospace motors," in IEEE Transactions on Industrial Electronics, vol. 67, no. 4, pp. 2618-2629, April 2020.

[13] IEC 60034-18-41, "Rotating electrical machines - Part 18-41: Partial discharge free electrical insulation systems (Type I) used in rotating electrical machines fed from voltage converters Qualification and quality control tests, " 2013.

[14] R. B. Abernethy, "The New Weibull Handbook," North Palm Beach (FL), 2004.

[15] T. W. Dakin, "Electrical Insulation Deterioration Treated as a Chemical Rate Phenomenon," in Transactions of the American Institute of Electrical Engineers, vol. 67, no. 1, pp. 113-122, Jan. 1948.

[16] G. Mazzanti, "The combination of electro-thermal stress, load cycling and thermal transients and its effects on the life of high voltage ac cables," in IEEE Transactions on Dielectrics and Electrical Insulation, vol. 16, no. 4, pp. 1168-1179, August 2009.

[17] P. Giangrande, et al., "Moving Toward a Reliability-Oriented Design Approach of Low-Voltage Electrical Machines by Including Insulation Thermal Aging Considerations," in IEEE Transactions on Transportation Electrification, vol. 6, no. 1, pp. 16-27, March 2020.

[18] Solvay, “Torlon ${ }^{\circledR}$ PAI - Design Guide," 2015.

[19] G. Biondi, "Polyesterimide wire enamels: coating with the right combination of thermal and mechanical properties for many applications," Macromol Mater Eng, 2008.

[20] V. Madonna, P. Giangrande and M. Galea, "Evaluation of strand-to-strand capacitance and dissipation factor in thermally aged enamelled coils for low-voltage electrical machines," in IET Science, Measurement \& Technology, vol. 13, no. 8, pp. 1170-1177, 102019. 